1 | P a g e

\title{
Requirement of HE-PIXE at High Z Elements in Charnockite Matrix Composition
}

\author{
Avupati Venkata Surya Satyanarayana ${ }^{1}$, Mokka Jagannadha Rao ${ }^{2}$, Byreddy Seetharami Reddy ${ }^{3}$ \\ 1 Department of Engineering Physics, Andhra University, Visakhapatnam-530003, AP, India. \\ 2 Department of Geology, Andhra University, Visakhapatnam-530003, A.P, India. \\ 3 Department of Nuclear Physics, Andhra University, Visakhapatnam-530003, AP, India. \\ Correspondence; A. V. S. Satyanarayana, E-mail; savs.viit@gmail.com
}

\begin{abstract}
;
The maximum of Proton Induced X-ray Emission analytical technique on metamorphic rocks in geology has used $3 \mathrm{MeV}$ range proton beams for excitation of thick targets. Protons of such energies do not accurately excite $\mathrm{K}-\mathrm{X}$-rays for high $\mathrm{Z}$ elements in matrix geological compositions like charnockite. In this analysis, low-energy PIXE (LE-PIXE) uses K-X-rays of Low Z elements and L-X-ray series for high Z elements. The resulting spectra between $\mathrm{K}$ $\mathrm{X}$-rays of light elements and L-X-rays of heavy elements can require striping techniques to resolve overlap difficulties in matrix composition. The results high $\mathrm{Z}$ elements in charnockite are to be expected, as the cross section for K-shell ionization of high- $Z$ elements have greater values in the proton energy range of greater than $3 \mathrm{MeV}$ in case of charnockite matrix composition. It has been suggested that the overlap of these discrete, gamma-rays with the Xray spectrum may be serious problem in charnockite high energy PIXE (HE-PIXE) work, sufficient to preclude its use as a viable analytical technique. The conclusion proves that for a very complex matrix charnockite material of unknown chemistry, a HE-PIXE analytical spectrum may contain various X-ray and gamma peaks, some of which may overlap, making the analysis of line identities and the evaluation of X-ray counts intractable. It does not however represent any intrinsic drawback in HE-PIXE, nor does it mean that HE-PIXE is any more or less intractable than many other nuclear analytical techniques. Alternatively, the same analytical tool use could be made of gamma-rays in HE-PIXE as in low energy analytical tools like PIGE, NRA or INAA to obtain the results of charnockite at high Z completely.
\end{abstract}

Keywords; LE-PIXE, Charnockite matrix, Overlap problems, HE-PIXE, K-X-rays, Detection probability, 
2 | P a g e

\section{Introduction}

Almost all of inner-shell ionisation cross section data is obtained out of total X-ray production cross sections, since X-ray detector systems are less complex. The X-ray spectrum associated with atom-energetic ion bombardment can be detected and quantified experimentally by means of general nuclear instruments. High resolution detection is often required and usually lithium drifted Silicon $\mathrm{Si}(\mathrm{Li})$ for minor and trace elements and high purity germanium (HPGe) detectors for detecting heavier atoms offer proper and resilient detection possibility suitable for complex nature of $\mathrm{X}$-ray spectra. Data is always received and transferred from detection system to a computer using suitable network procedure in order to work out the quantifying that involves the analytical interpretation of the X-ray spectrum and peak area measurements.

Particle Induced X-ray Emission (PIXE) (Johansson and Campbell, 1988) is the technique where $\mathrm{X}$-rays are induced by the impact of energetic ions due to the coulomb interaction between the incident ion and inner-shell bound electron, giving rise to vacancy in the sample atom. This created vacancy is as a result filled by an outer shell electron, and the atom subsequently de-excites by emitting a characteristic X-ray. In multi-elemental samples, each element in the sample can be identified and quantified by referring to its characteristic $\mathrm{X}$-rays. The study of X-rays produced by light ions bombardments has received a great impetus by the modifications of analytical techniques. Protons of energy 2-5 MeV are found to be the most suitable ionising agents to use for the PIXE principle as one of the leading multi-elemental analysis technique. PIXE has comparably large cross sections when compared to the other excitation processes. As a result, the characteristic X-rays are produced in concentration with relatively low background interference and only a low amount of sample's composition is required for the analysis. If everything works well under valid conditions, it is possible to detect 1-2 parts per million in quantities over a number of elements.

The PIXE analytic technique is a non-destructive, non-invasive, no sample surface contamination and do not affect the analysis since PIXE is usually insensitive to elements with $Z<13$. We examine experimental factors in the latest successes of proton Microprobe (PMP) experiments in the geological materials. The PIXE analysis can now be efficient to scientists belongs to geology (Campbell and Willcam, 1995) as a useful, common and measurement tool. With modifying suitability of proton microprobes and awareness among geo scientists of the efficiencies of PIXE, matrix geo material applications (Ryan, 2004) are likely to increase rapidly. Ore deposit mineralogy studies are performed to achieve a wide range of objectives like parameters useful for mineral exploration is to a complete minerals characterization (Graham, et. al., 2002) necessary to give guidance for mineral beneficiation and extraction. Trace-element information, to calculate partition coefficients between coexisting minerals, or on fluid inclusions, provides geothermometric data on ore deposits.

PIXE through high sensitivity and accuracy multi element measurement (Christopher, et. al., 2016) with picometer spatial resolution offers up new capabilities in inter disciplinary research work. Trace element data achieved using the proton microprobe provides new 
analytical tools in ore genesis studies, exploration for precious metals, as well in the processing of metal bearing ores. Introduction of this new methodology to the complex materials however is controlled by economic factors which must be taken into consideration. Matrix geological material has gained new studies with the availability and application of PIXE, XRF and EMPA and NAA (Malmqvist, et. al., 1987) complementary analytical techniques (Satyanarayana, et. al., 2020).

A lot of PIXE work on geological materials has used $3 \mathrm{MeV}$ energy range proton beams for thick samples and excitation. Proton beams of such energies do not suitably excite K-Xrays for high $\mathrm{Z}$ elements present in charnockite complex composition, and low-energy PIXE generally uses the L-X-rays for high $\mathrm{Z}$ elements. The final spectra of complex matrix can require techniques of striping to resolve interfere problems between $\mathrm{X}$-rays of low to high $\mathrm{Z}$ elements in charnockite composition. Previously, it was thought that PIXE technique of geological materials was restricted to excitation protons in the $3 \mathrm{MeV}$ energy range. Because, PIXE with $3 \mathrm{MeV}$ failed to detect (Javier, 1996) very low $\mathrm{Z}$ elements due to detector limits and also at high $\mathrm{Z}$ elements and hence overlapping of these L-X-rays of high $\mathrm{Z}$ with $\mathrm{K}-\mathrm{X}$ rays of low and middle $Z$ elements, detection not is possible (Satyanarayana, et. al., 2020). Simultaneously K-X-rays cross sections are heavy, so $3 \mathrm{MeV}$ proton is not sufficient to excite the elements at high $\mathrm{Z}$ elements. To analyse the charnockite composition completely including high $\mathrm{Z}$ elements using PIXE, according to previous literature of charnockite and geological research, most probably HE-PIXE may enable.

Since, PIXE is a highly sensitive, accurate and non-destructive analytical method for different elements in variety geological materials down to the levels of a few ppm. The samples chosen for analytical method are collected from the middle portion of a charnockite hill, Visakhapatnam airport A.P, during a demolition operation for expansion of the airport. A big lenticular mass compositionally different from the host charnockite rock was identified in the middle part of the hill. This body is believed to be the early crustal layer (possibly proto crust). Such samples are rare, PIXE technique is chosen for the trace elemental analysis of these rare samples.

\section{Methodology}

The elemental quantification of charnockite matrix in each sample was concentrated using the proton beam PIXE measurements. Each target's was bombarded with beam of 3 $\mathrm{MeV}$ protons in our PIXE set-up (Johansson and Johansson, 1976) X-ray spectra was obtained and noted for all the measurements. While taking these experiments there was constant keeping close tabs on the beam current, dead-time and beam aperture as all these play an important role in the quality of the received spectrum. Beam is lead to the beam line through the analysing magnets; afterwards they pass through the collimator to keep the beam in focus as they approach the sample. To measure proton beam current, Beam Profile Monitor (BPM) is used, and is placed in vacuum before the exit window where the proton beam enters the atmosphere of laboratory.

Experiments were carried out at the scanning nuclear microprobe arranged on the 0 beam line of the $3 \mathrm{MV}$ pelletron accelerator at Institute of Physics, Bhubaneswar, India. 
4 I P a g e

Concerning the measurement conditions, a proton beam of $3 \mathrm{MeV}$ energy focused down to diameter $80 \mathrm{~mm}^{2}$ with a $20 \mathrm{nA}$ beam current used to bombard the targets. In order to avoid the charging up of the samples, the proton beam current had to be kept under same. For the low $\mathrm{Z}$ elements PIXE measurements, relative to the incident beam, X-ray detector placed at $135^{\circ}$ geometry were used to detect the induced characteristic X-rays. A Gresham type $\mathrm{Si}(\mathrm{Li})$ $\mathrm{X}$-ray Be windowed detection with $80 \mathrm{~mm} 2$ active diameter setup was used to calculate the medium and high energy characteristic X-rays (Atomic number > 19, energy 3-30 keV). From the scattered protons, the detector protected by a permanent magnet and with a beam chopper, the accumulated charge was monitored.

At an angle of $45^{\circ}$ with direction to the proton beam, the charnockite targets which are to be positioned on the target holder in this scattering chamber. The position of the target relative to the beam direction is arranged suitably by observing through a window in the scattering chamber. The detector is positioned at an angle of $90^{\circ}$ with respect to the beam direction. A Si (Li) with high detection (160 eV FWHM at $5.9 \mathrm{KeV})$ is used in the present study to count the X-ray spectrum. Detailed explanation of the measurement setup can be found and signal from all detection were collected by the data acquisition system. PIXE spectra with better resolution and lower dead time were recorded.

The recorded PIXE spectra were evaluated with the GUPIX software (Maxwell, 1995) to determine the multi elemental composition of the targets or samples. At first, the composition of the matrix was calculated from the spectra of the $\mathrm{Si}$ (Li) detection, and then the spectra of the Be windowed detector was analysed in element mode. On the spectra of detection, the X-ray energy range of $2-8.5 \mathrm{keV}$ is common, therefore characteristic X-rays within this energy range was used to normalize the elemental quantifications. In the starting and at the completion of the measurement experiments, analyses of standard reference materials were carried out in order to verify the performance of the dose calculation and of the precision, accuracy of the PIXE analysis setup. The standard USGS reference material Basalt standards were used.

\section{Results}

The PIXE spectrum of the seven matrix charnockite samples collected from the interior of the hill. The quantifications in ppm of these wide ranges of elements in each target were calculated using the GUPIX software with Si (Li) detection (Satyanarayana, et. al., 2016). These concentrations are tabulated with errors in table-1 by using the analysis of PIXE spectrum. The missing elements in the PIXE spectrum of Charnockite samples with respect to previous analytical techniques and hence the experimental factors behind the analysis of charnockite matrix samples by PIXE at $3 \mathrm{MeV}$ are discussed. With the comparison present results table-1 and table-2 of previous studies (Rao, et. al., 1969, Rao and Babu, 1978, Kamineni, et. al., 1982, Rao, et. al., 1993) the elements in charnockite composition is discussed and suggestions for high $\mathrm{Z}$ elements detection in charnockite are made with probable HE-PIXE. 
Table -1; Analytical results of all matrix charnockite samples (PIXE)

\begin{tabular}{|c|c|c|c|c|c|c|c|c|}
\hline S.NO & Element & G1 & G2 & G3 & G4 & G5 & G6 & G7 \\
\hline 1 & $\mathrm{Cl}$ & $394.1 \pm 16.5$ & $399.6 \pm 17.1$ & $379 \pm 16.5$ & $403.5 \pm 19.5$ & $546.9 \pm 23.5$ & $383.7 \pm 16.7$ & $462.6 \pm 20.6$ \\
\hline 2 & K & $4080 \pm 28.2$ & $4187 \pm 25.1$ & $4148 \pm 26.1$ & $4246 \pm 29.3$ & $6699 \pm 40.2$ & $5458 \pm 27.1$ & $5393 \pm 33.4$ \\
\hline 3 & $\mathrm{Ca}$ & $2229 \pm 25.9$ & $2281 \pm 22.8$ & $2637 \pm 25.6$ & $2754 \pm 28.1$ & $4120 \pm 23.5$ & $2544 \pm 26.2$ & $3091 \pm 32.1$ \\
\hline 4 & $\mathrm{Ti}$ & $1394 \pm 11.6$ & $1271 \pm 9.3$ & $1109 \pm 9.3$ & $13.67 \pm 11.3$ & $1590 \pm 13.8$ & $1044 \pm 9.1$ & $1510 \pm 12.4$ \\
\hline 5 & V & $17.92 \pm 4.8$ & $23.69 \pm 4.1$ & $7.85 \pm 4.0$ & BDL & $37.78 \pm 6.0$ & $10.79 \pm 4.0$ & $11.55 \pm 12.4$ \\
\hline 6 & $\mathrm{Cr}$ & $16.63 \pm 2.3$ & $38.53 \pm 2.1$ & $15.16 \pm 2.1$ & $16.93 \pm 2.5$ & $17.71 \pm 3.1$ & $9.118 \pm 2.1$ & $14.13 \pm 2.6$ \\
\hline 7 & $\mathrm{Mn}$ & $18.62 \pm 3.9$ & $34.71 \pm 3.7$ & $34.31 \pm 3.7$ & $33.68 \pm 4.1$ & $47.43 \pm 5.3$ & $27.36 \pm 3.5$ & $27.03 \pm 4.5$ \\
\hline 8 & $\mathrm{Fe}$ & $5200 \pm 20.3$ & $6575 \pm 21.0$ & $5649 \pm 19.8$ & $5838 \pm 22.2$ & $7325 \pm 26.4$ & $4905 \pm 17.7$ & $6238 \pm 23.1$ \\
\hline 9 & $\mathrm{Ni}$ & $10.96 \pm 3.7$ & $11.43 \pm 3.7$ & $10.06 \pm 3.39$ & $8.94 \pm 3.92$ & $28.29 \pm 5.02$ & $10.11 \pm 3.1644$ & $16.5 \pm 4.3692$ \\
\hline 10 & $\mathrm{Cu}$ & BDL & BDL & $6.1 \pm 2.7$ & BDL & BDL & BDL & $8.717 \pm 3.47$ \\
\hline 11 & $\mathrm{Zn}$ & $9.147 \pm 3.3$ & $18.21 \pm 3.5$ & $14.23 \pm 3.0$ & $14.41 \pm 3.5$ & 11.96. \pm 4.6 & $24.73 \pm 2.9$ & $4.29 \pm 2.0$ \\
\hline 12 & $\mathrm{Se}$ & $6.3 \pm 65 \pm 2.5$ & BDL & BDL & $0.9499 \pm 1.7$ & BDL & BDL & BDL \\
\hline 13 & $\mathrm{Br}$ & $4 \pm 2.2$ & $12.17 \pm 2.93$ & $11.82 \pm 2.85$ & $13.47 \pm 6.2$ & $10.32 \pm 4.031$ & $8.61 \pm 2.455$ & $9.08 \pm 3.503$ \\
\hline 14 & $\mathrm{Rb}$ & $48.87 \pm 6.0$ & $42.08 \pm 6.1$ & $62.73 \pm 6.0$ & $34.71 \pm 6.2$ & $56.14 \pm 7.9$ & $34.58 \pm 5.3$ & $52.46 \pm 7.1$ \\
\hline 15 & $\mathrm{Sr}$ & $38.5 \pm 5.4$ & $28.6 \pm 4.6$ & $44.61 \pm 4.9$ & $27.65 \pm 5.2$ & $38.02 \pm 6.5$ & $33.91 \pm 4.9$ & $35.53 \pm 6.1$ \\
\hline 16 & $\mathrm{Y}$ & BDL & $12.64 \pm 4.5$ & BDL & $18.13 \pm 5.0$ & BDL & BDL & BDL \\
\hline 17 & $\mathrm{Zr}$ & $95.91 \pm 9.8$ & $20.86 \pm 6.0$ & $23.6 \pm 6.1$ & $63.7 \pm 8.7$ & $11.44 \pm 7.0$ & $12.16 \pm 5.0$ & $77.82 \pm 9.3$ \\
\hline 18 & $\mathrm{Nb}$ & $7.035 \pm 3.1$ & $9.812 \pm 3.9$ & BDL & $6.09 \pm 3.29$ & BDL & BDL & BDL. \\
\hline 19 & Mo & BDL & $24.34 \pm 6.3$ & BDL & $10.84 \pm 4.04$ & BDL & BDL & BDL \\
\hline 20 & $\mathrm{Ru}$ & BDL & BDL & BDL & BDL & BDL & $9.977 \pm 3.59$ & BDL \\
\hline 21 & $\mathrm{Ag}$ & BDL & $12.36 \pm 9.0$ & BDL & BDL & BDL & BDL & BDL \\
\hline 22 & $\mathrm{~Pb}$ & $32.93 \pm 15.6$ & $38.35 \pm 17.3$ & $17.68 \pm 7.7$ & $28.82 \pm 11.2$ & $41.58 \pm 14.48$ & BDL & $24.49 \pm 12.5$ \\
\hline
\end{tabular}


Table-2; Results of charnockites of same area of previous analyses and present PIXE

\begin{tabular}{|c|c|c|c|c|}
\hline Element & Atomic Number & $\begin{array}{l}\text { Present PIXE } \\
\text { Analysis, average of } \\
7 \text { samples }\end{array}$ & $\begin{array}{l}\text { Previous Chemical } \\
\text { analysis of pyroxene } \\
\text { granulites from } \\
\text { charnockitic rocks, } \\
\text { Visakhapatnam } \\
\text { (Rao, et. al., 1993) }\end{array}$ & $\begin{array}{l}\text { Previous, Chemical } \\
\text { analysis of allanite } \\
\text { from Air Port Hill } \\
\text { charnockite, } \\
\text { Visakhapatnam (Rao } \\
\text { and Babu, 1978) }\end{array}$ \\
\hline $\mathrm{Li}$ & 3 & ND & $18.08 \mathrm{ppm}$ & - \\
\hline $\mathrm{Be}$ & 4 & ND & - & $<4$ \\
\hline $\mathrm{F}$ & 9 & ND & $0.400 \mathrm{ppm}$ & - \\
\hline $\mathrm{Na}$ & 11 & ND & $\mathrm{Na}_{2} \mathrm{O}=1.591(\mathrm{Wt} \%)$ & - \\
\hline $\mathrm{Mg}$ & 12 & ND & $\mathrm{MgO}=4.022(\mathrm{Wt} \%)$ & $\mathrm{MgO}=1.18(\mathrm{Wt} \%)$ \\
\hline $\mathrm{Al}$ & 13 & ND & $\mathrm{Al}_{2} \mathrm{O}_{3}=18.137(\mathrm{Wt} \%)$ & $\mathrm{Al}_{2} \mathrm{O}_{3}==14.79(\mathrm{Wt} \%)$ \\
\hline $\mathrm{Si}$ & 14 & ND & $\mathrm{SiO}_{2}=50.345(\mathrm{Wt} \%)$ & $\mathrm{SiO}_{2}=31.24(\mathrm{Wt} \%)$ \\
\hline $\mathrm{P}$ & 15 & ND & $\mathrm{P}_{2} \mathrm{O}_{5}=0.213(\mathrm{Wt} \%)$ & - \\
\hline $\mathrm{Cl}$ & 17 & $424.2 \pm 18.62 \mathrm{ppm}$ & $0.130 \mathrm{ppm}$ & - \\
\hline $\mathrm{K}$ & 19 & $4887.28 \pm 29.91 \mathrm{ppm}$ & $\mathrm{K}_{2} \mathrm{O}=0.428(\mathrm{Wt} \%)$ & - \\
\hline $\mathrm{Ca}$ & 20 & $2808 \pm 26.31 \mathrm{ppm}$ & $\mathrm{CaO}=11.376(\mathrm{Wt} \%)$ & $\mathrm{CaO}=11.01(\mathrm{Wt} \%)$ \\
\hline $\mathrm{Sc}$ & 21 & ND & $23 \mathrm{ppm}$ & $150 \mathrm{ppm}$ \\
\hline $\mathrm{Ti}$ & 22 & $1133.09 \pm 10.97 \mathrm{ppm}$ & $\mathrm{TiO}_{2}=1.314(\mathrm{Wt} \%)$ & $\mathrm{TiO}_{2}=1.62(\mathrm{Wt} \%)$ \\
\hline $\mathrm{V}$ & 23 & $18.26 \pm 5.88 \mathrm{ppm}$ & $240 \mathrm{ppm}$ & $\mathrm{V}_{2} \mathrm{O}_{3}=0.09(\mathrm{Wt} \%)$ \\
\hline $\mathrm{Cr}$ & 24 & $18.31 \pm 2.4 \mathrm{ppm}$ & $180 \mathrm{ppm}$ & $70 \mathrm{ppm}$ \\
\hline $\mathrm{Mn}$ & 25 & $31.934 \pm 4.1 \mathrm{ppm}$ & $\mathrm{MnO}=0.089(\mathrm{Wt} \%)$ & $\mathrm{MnO}=0.28(\mathrm{Wt} \%)$ \\
\hline $\mathrm{Fe}$ & 26 & $5961.42 \pm 21.5 \mathrm{ppm}$ & $\begin{array}{l}\mathrm{Fe}_{2} \mathrm{O}_{3}=1.123(\mathrm{Wt} \%) \\
\mathrm{FeO}=10.649(\mathrm{Wt} \%)\end{array}$ & $\begin{array}{l}\mathrm{Fe}_{2} \mathrm{O}_{3}=5.10(\mathrm{Wt} \%) \\
\mathrm{FeO}=8.49(\mathrm{Wt} \%)\end{array}$ \\
\hline Co & 27 & ND & 74ppm & $150 \mathrm{ppm}$ \\
\hline $\mathrm{Ni}$ & 28 & $13.755 \pm 3.89 \mathrm{ppm}$ & $170 \mathrm{ppm}$ & $66 \mathrm{ppm}$ \\
\hline $\mathrm{Cu}$ & 29 & $7.40 \pm 3.08 \mathrm{ppm}$ & $262 \mathrm{ppm}$ & $150 \mathrm{ppm}$ \\
\hline $\mathrm{Zn}$ & 30 & $13.85 \pm 3.25 \mathrm{ppm}$ & $80 \mathrm{ppm}$ & $140 \mathrm{ppm}$ \\
\hline $\mathrm{G}$ & 31 & ND & $36 \mathrm{ppm}$ & $30 \mathrm{ppm}$ \\
\hline $\mathrm{Ge}$ & 32 & $\mathrm{ND}$ & - & $80 \mathrm{ppm}$ \\
\hline $\mathrm{Se}$ & 34 & $3.65 \pm 2.1 \mathrm{ppm}$ & - & - \\
\hline $\mathrm{Br}$ & 35 & $9.92 \pm 3.45 \mathrm{ppm}$ & - & - \\
\hline $\mathrm{Rb}$ & 37 & $47.36 \pm 6.37 \mathrm{ppm}$ & 66.52ppm & - \\
\hline $\mathrm{Sr}$ & 38 & $35.26 \pm 5.37 \mathrm{ppm}$ & $325 \mathrm{ppm}$ & 480ppm \\
\hline $\mathrm{Y}$ & 39 & $15.385 \pm 4.75 \mathrm{ppm}$ & - & $* \mathrm{Y}_{2} \mathrm{O}_{3}=0.15(\mathrm{Wt} \%)$ \\
\hline $\mathrm{Zr}$ & 40 & $43.64 \pm 7.41 \mathrm{ppm}$ & $78 \mathrm{ppm}$ & $* \mathrm{ZrO}_{2}=0.15(\mathrm{Wt} \%)$ \\
\hline $\mathrm{Nb}$ & 41 & $7.6 \pm 3.43 \mathrm{ppm}$ & - & 900ppm \\
\hline Mo & 42 & $17.59 \pm 5.17 \mathrm{ppm}$ & - & $60 \mathrm{ppm}$ \\
\hline $\mathrm{Ru}$ & 44 & $9.97 \pm 3.59 \mathrm{ppm}$ & - & - \\
\hline $\mathrm{Ag}$ & 47 & $12.36 \pm 9.0 \mathrm{ppm}$ & - & - \\
\hline Sn & 50 & ND & - & $* \mathrm{SnO}_{2}=0.03(\mathrm{Wt} \%)$ \\
\hline $\mathrm{Ba}$ & 56 & ND & $338.40 \mathrm{ppm}$ & - \\
\hline $\mathrm{Hf}$ & 72 & ND & $3.23 \mathrm{ppm}$ & - \\
\hline $\mathrm{Ta}$ & 73 & ND & $0.69 \mathrm{ppm}$ & - \\
\hline $\mathrm{W}$ & 74 & ND & - & $<40 \mathrm{ppm}$ \\
\hline$\overline{\mathrm{Au}}$ & 79 & ND & - & $10 \mathrm{ppm}$ \\
\hline $\mathrm{Pb}$ & 82 & $30.64 \pm 13.13 \mathrm{ppm}$ & - & $* \mathrm{PbO}=0.04(\mathrm{Wt} \%)$ \\
\hline $\mathrm{Th}$ & 90 & $\mathrm{ND}$ & $7.07 \mathrm{ppm}$ & $* \mathrm{ThO}_{2}=0.50(\mathrm{Wt} \%)$ \\
\hline $\mathrm{U}$ & 92 & ND & $2.83 \mathrm{ppm}$ & $* \mathrm{U}_{3} \mathrm{O}_{8}=0.01(\mathrm{Wt} \%)$ \\
\hline REE & 57 to 71 & ND & - & $\begin{array}{l}*(\mathrm{Ce}, \mathrm{La}, \mathrm{Nd})_{2} \mathrm{O}_{3}= \\
23.29(\mathrm{Wt} \%)\end{array}$ \\
\hline
\end{tabular}


7 | P a g e

\section{Discussion}

From the applications of LE-PIXE $3 \mathrm{MeV}$ using $\mathrm{Si}$ (Li) detectors and above charnockite analysis (Satyanarayana and Ravi Kumar, 2017) suggested that it would be advantageous to keep excitation energies as low as possible to "reduce the number of different nuclear reactions" that might contribute low-energy gamma-ray peaks to the spectrum. The occurrence of various gamma-ray interferences is distinct from problems related to background (Murozono, et. al., 1999). The important sources for continuous background radiation in the low energy PIXE spectrum are atomic, secondary electron and quasi-free electron bremsstrahlung. These backgrounds mainly determine the limit of detection in PIXE spectrum by underlying the characteristic X-ray peaks in the case of elements with $\mathrm{Z}<35$. Other factors forming the background are nuclear bremsstrahlung (Ishii, et. al., 2005) the Compton tail of $\gamma$-rays, which is induced by the nuclear reactions.

The drawback of PIXE at $3 \mathrm{MeV}$ to studying in this configuration is that below or near the chlorine (Satyanarayana, et. al., 2020) from spectrums of PIXE are not detected in this work due to low energy X-rays, because they are absorbed in either the detector window atmosphere or through any filter used. In case of PIXE analysis of the elements present in charnockite with $\mathrm{Z} \leq 31$ an interference is encountered between the $\mathrm{K} \alpha$ next element $\mathrm{X}$-ray and the $\mathrm{K} \beta$ previous element $\mathrm{X}$-ray, which have virtually the same energy and also between the $\mathrm{X}$-ray $\mathrm{K}$ lines of media elements and $\mathrm{X}$-ray $\mathrm{L}$ lines of heavy elements. Due to this the concentration values of $\mathrm{Ca}, \mathrm{K}, \mathrm{Ti}, \mathrm{V}, \mathrm{Cr}, \mathrm{Mn}, \mathrm{Fe}, \mathrm{Ni}, \mathrm{Cu}, \mathrm{Zn}, \mathrm{Se}, \mathrm{Br}, \mathrm{Rb}, \mathrm{Sr}, \mathrm{Y}, \mathrm{Zr}, \mathrm{Nb}, \mathrm{Mo}$, $\mathrm{Ru}, \mathrm{Ag}, \mathrm{Pb}$ are not exactly equal to the concentrations when compare to the another analytical techniques. Few elements like $\mathrm{Li}, \mathrm{Be}, \mathrm{F}, \mathrm{Co}, \mathrm{Ga}, \mathrm{Ge}, \mathrm{Ce}, \mathrm{Sn}, \mathrm{Ba}, \mathrm{Au}, \mathrm{Th}, \mathrm{U}$ and REE are not detected due to the same reason.

Particle Induced X-ray Emission (PIXE) has been used to an analytical tool for long range of major, minor, trace and REE elemental analysis in Precambrian charnockites. PIXE is sensitive, accurate and non-destructive method for some elemental analysis in a variety of metamorphic charnockite rocks down to levels of a few ppm and it is not valid for all remaining elements in the composition. The elements in the Precambrian charnokite rock $\mathrm{Cl}$, $\mathrm{K}, \mathrm{Ca}, \mathrm{Ti}, \mathrm{V}, \mathrm{Cr}, \mathrm{Mn}, \mathrm{Fe}, \mathrm{Ni}, \mathrm{Cu}, \mathrm{Zn}, \mathrm{Se}, \mathrm{Br}, \mathrm{Rb}, \mathrm{Sr}, \mathrm{Y}, \mathrm{Zr}, \mathrm{Nb}, \mathrm{Mo}, \mathrm{Ru}, \mathrm{Ag}, \mathrm{Pb}$ are identified without exact values by PIXE but the minor and major elements $\mathrm{Li}$. Be, F, Na, Mg, Al, Si, P, $\mathrm{Ba}$ and traces of Sc, Ce, Co, Sn, W, Ge, Ga, Au, Th, U and REE are not at all detected due to the various factors even though there present in the charnockite composition, because of PIXE which is operated at $3 \mathrm{MeV}$ proton energy and characterization of charnockite compositional investigated. In elemental characterization of charnockite rocks, elemental errors in concentration explained by comparing nuclear technique studies.

The element tin 3.444, $3.663 \mathrm{keV}$ (L-X-rays) are similar to the potassium K-X-rays. Therefore tin is not detected in charnockite composition by PIXE analysis. The element barium 4.466, $4.82822 \mathrm{keV}$ (L-X-rays) since K-X-rays limited in case of PIXE and for L-Xrays, similar to titanium $4.512,4.933 \mathrm{keV}$ (K-X-rays). Therefore barium is present in the charnockite composition, but not detected in PIXE analysis due to the above reason. The 
element cerium have 4.839, $5.262 \mathrm{keV}$ (L-X-rays), these L-X-ray energies are same as titanium $4.933 \mathrm{keV}$ (K-X-rays), Vanadium $4.9535 .428 \mathrm{keV}$ (L-X -rays). Therefore cerium is not identified in PIXE spectrum and overlapped with either titanium or vanadium.

The rare earth elements are also very important but not detected by using PIXE with 3 $\mathrm{MeV}$ analyses. The M-X-rays of rare earth elements and $\mathrm{Hf}$, Ta, and $\mathrm{W}$ have less energy characteristic X-rays and absorbed by the detector window. The element Hf have L-X-ray energies 7.899, $9.023(\mathrm{keV})$ and $\mathrm{M}$-X-ray energies 1.646, $1.700(\mathrm{keV})$, Ta have L-X-ray energies 8.146, $9.343(\mathrm{keV})$ and $\mathrm{M}$-X-ray energies 1.712, $1.770(\mathrm{keV}), \mathrm{W}$ have L-X-ray energies 8.398, $9.672(\mathrm{keV})$ and M-X-ray energies 1.775, $1.838(\mathrm{keV})$. Similarly Co have KX-ray energy $7.649(\mathrm{keV})$, Ni have K-X-ray energy $8.267(\mathrm{keV}), \mathrm{Cu}$ have K-X-ray energy 8.046, $8.904(\mathrm{keV}), \mathrm{Zn}$ have K-X-ray energy $9.570(\mathrm{keV})$ and Ga have K-X-ray energy 9.251 $(\mathrm{keV})$. From the above discussion, M-X-ray energies of the elements $\mathrm{Hf}, \mathrm{Ta}, \mathrm{W}$ have less characteristic energies are detected by PIXE and L-X-ray energies are nearly equal to K-Xray energies of $\mathrm{Co}, \mathrm{Ni}, \mathrm{Cu}, \mathrm{Zn}, \mathrm{Ga}$ and $\mathrm{Ge}$. Since Ga have 9.251, 10.267 (K-X-rays) and 1.098, 1.125 (L-X-rays), Ge have 9.886, 10.982 (K-X-rays) and 1.188, 1.218 (L-X-rays). Therefore Hf, Ta, W and rare earth element are not identified in the PIXE spectrum of charnockite composition in this PIXE at $3 \mathrm{MeV}$ methodology. Similarly Au have L-X-rays 9.713, $11.443 \mathrm{keV}$, Ge have 9.886, $10.982 \mathrm{keV}$ L-X-rays, Ga have 9.251, $10.267 \mathrm{keV} \mathrm{L-X-}$ rays at similar characteristic X-ray energies. Therefore the elements $\mathrm{Au}, \mathrm{Ge}$ and $\mathrm{Ga}$ are not detected in PIXE experiments but these are already presented in the charnockite composition in the form of traces by other previous techniques.

PIXE with $3 \mathrm{MeV}$ energy protons is not the technique of choice for the REE in complex matrix charnockite shown in table-1 whose levels of uninterested are after at the ppm level or below. Because the REE elements present in matrix charnockite composition, But charnockite have characteristic X-rays Lanthanum $\mathrm{K} \alpha 33.442 \mathrm{keV}$ and $\mathrm{L} \alpha 4.64 \mathrm{keV}$, Cerium L $\alpha 4.839 \mathrm{keV}$ and $\mathrm{M} \alpha 0.884 \mathrm{keV}$, Praseodymium L $\alpha 5.035 \mathrm{keV}$ and $\mathrm{M} \alpha 0.927 \mathrm{keV}$, Neodymium La $5.228 \mathrm{keV}$ and $\mathrm{M} \alpha 0.979 \mathrm{keV}$, Promethium La $5.432 \mathrm{keV}$ and $\mathrm{M} \alpha 1.023$ $\mathrm{keV}$, Samarium $\mathrm{L} \alpha 5.633 \mathrm{keV}$ and $\mathrm{M} \alpha 1.078 \mathrm{keV}$, Europium $\mathrm{L} \alpha 5.849 \mathrm{keV}$ and $\mathrm{M} \alpha 1.131$ $\mathrm{keV}$, Gadolinium L $\alpha 6.053 \mathrm{keV}$ and $\mathrm{M} \alpha 1.181 \mathrm{keV}$, Terbium L $\alpha 6.273 \mathrm{keV}$ and $\mathrm{M} \alpha 1.240$ $\mathrm{keV}$, Dysprosium L $\alpha 6.498 \mathrm{keV}$ and $\mathrm{M} \alpha 1.293 \mathrm{keV}$, Holmium L $\alpha 6.720 \mathrm{keV}$ and $\mathrm{M} \alpha 1.348$ $\mathrm{keV}$, Erbium L $\alpha .949 \mathrm{keV}$ and $\mathrm{M} \alpha 1.404 \mathrm{keV}$, Thulium L $7.180 \mathrm{keV}$ and $\mathrm{M} \alpha 1.462 \mathrm{keV}$, Ytterbium L $\alpha .416 \mathrm{keV}$ and $\mathrm{M} \alpha 1.526 \mathrm{keV}$, Lutetium L $7.655 \mathrm{keV}$ and $\mathrm{M} \alpha 1.580 \mathrm{keV}$.

In the above REE elements, K-X ray energies are very high and due to the cross sections these are not detected by PIXE with $3 \mathrm{MeV}$. The M-X rays of REE are very low, absorbed by the $\mathrm{Si}(\mathrm{Li})$ detector. Finally L-X-ray energies are in the range of PIXE experiment at $3 \mathrm{MeV}$, but these LX-ray energies of REE 4.6-7.6 KeV are overlapped with the following K-X-ray media Z elements like Titanium $\mathrm{K} \alpha 4.512 \mathrm{keV}$ and $\mathrm{L} \alpha 0.452 \mathrm{keV}$, Vanadium $\mathrm{K} \alpha 4.953 \mathrm{keV}$ and $\mathrm{L} \alpha 0.510 \mathrm{keV}$, Chromium $\mathrm{K} \alpha 5.415 \mathrm{keV}$ and $\mathrm{L} \alpha 0.572 \mathrm{keV}$, Manganese $\mathrm{K} \alpha 5.900 \mathrm{keV}$ and $\mathrm{L} \alpha 0.637 \mathrm{keV}$, Iron $\mathrm{K} \alpha 6.405 \mathrm{keV}$ and $\mathrm{L} \alpha 0.705 \mathrm{keV}$, Cobalt $\mathrm{K} \alpha 6.931 \mathrm{keV}$ and $\mathrm{L} \alpha 0.775 \mathrm{keV}$, Nickel $\mathrm{K} \alpha 7.480 \mathrm{keV}$ and $\mathrm{L} \alpha 0.849 \mathrm{keV}$, Copper Ka 8.046 $\mathrm{keV}$ and $\mathrm{L} \alpha 0.928 \mathrm{keV}$. 
Thorium and Uranium traces are not detected by using present analysis. Because of uranium, contain $98.440 \mathrm{keV}, 111.303 \mathrm{keV}$ (K-X-rays), $13.614 \mathrm{keV} 17.220 \mathrm{keV}$ (L-X-rays) and $3.171 \mathrm{keV} 3.336 \mathrm{keV}$ (M-X-rays), similarly thorium contain $93.351 \mathrm{keV} 105.605 \mathrm{keV}$ (K-X-rays), $12.968 \mathrm{keV} 16.202 \mathrm{keV}$ (L-X-rays) and $2.996 \mathrm{keV} 3.149 \mathrm{keV}$ (M-X-rays). The $\mathrm{X}$ - ray energy detection from PIXE with $\mathrm{Si}(\mathrm{Li})$ detector experiment should only lay 1-20 $\mathrm{keV}$. The energy of K-X-ray energies of high $\mathrm{Z}$ elements in charnockite composition are more, therefore detection is not possible through $\mathrm{K}-\mathrm{X}$ rays due to the $\mathrm{Si}(\mathrm{Li})$ detector limitation. But the atomic number of Th and $\mathrm{U}>83$, according to PIXE theory, M-X-rays are limited to PIXE technique because for M-X-rays, validity is $72<\mathrm{Z}<83$. Finally $\mathrm{L} \mathrm{X}$-rays energies of Th and $\mathrm{U}$ are similar to $\mathrm{K} X$-rays energies of $\mathrm{Br} 13.292 \mathrm{keV}, \mathrm{Rb} 13.396 \mathrm{keV}, \mathrm{Sr}$ $15.835 \mathrm{keV}$, and Mo $17.480 \mathrm{keV}$, which are present in the composition shown in table-1. Therefore, due to above reason or overlapping $\mathrm{U}$ and $\mathrm{Th}$ are not detected in charnockite composition by PIXE with $3 \mathrm{MeV}$ spectrum analyses.

In case of PIXE spectrum analysis of the elements present in charnockite, the elements $\mathrm{Z} \leq 31$ an overlap is occurred between the $\mathrm{K} \alpha$ immediate element $\mathrm{X}$-ray and the $\mathrm{K} \beta$ previous element X-ray, which have virtually the same characteristic energy or between the X-ray $\mathrm{K}$ lines of media elements and X-ray L lines of heavy elements. Determination of rare earth elements in charnockite samples is a very important, but is not easy to tackle in this investigation. By PIXE at $3 \mathrm{MeV}$, the $\mathrm{L} \mathrm{X-rays} \mathrm{energies} \mathrm{of} \mathrm{low} \mathrm{Z}$ elements from 4-9 keV range of REE in charnockite strongly interfere with $\mathrm{K} \mathrm{X}$-rays energies of low $\mathrm{Z}$ elements (20 to $31 \mathrm{Z}$ ) and the quantification of REE by PIXE with $3 \mathrm{MeV}$ becomes very difficult detect in this study.

Interferences of various peaks of low $\mathrm{Z}$ to high $\mathrm{Z}$ elements present in charnockite caused by overlap of L-X-ray line and $\mathrm{X}$-ray lines are not easily resolved, mainly when one is important in analysis of the rare earth elements. As the REEs are of very important to the geologists and there is not yet an interesting technique for their analysis, it is important that the full potential of be realized for this group. The full complexity of the difficulties is revealed by the interpreted spectrum of charnockite, a rare earth containing charnockite composition, presented in this study. That this complex spectrum could be interpreted with such precision was a major toured force but not the type of experiment that would be appropriate for routine analysis. To eliminate these interfere separation of REE from the matrix or by analysing the $\mathrm{K}-\mathrm{X}$-rays instead of the L-X-rays for the rare earth elements in a charnockite sample approach should be modified at the proton energies.

From the above study held that the maximum energy for PIXE analysis laid $3 \mathrm{MeV}$ range. Above $3 \mathrm{MeV}$ range increasing backgrounds arising due to compound nuclear reaction gamma rays offset the advantage of higher $\mathrm{X}$-ray production cross sections. In general above proton energies $20 \mathrm{MeV}$, various particle processes overcomes and different gamma-rays are lost in background spectra. In the range above proton energy $60 \mathrm{MeV}$ for elements at high Z, the maximum in cross sections for K-X-ray production is reached (Norman, et. al., 1995). The mixing of higher production cross section and continuum gamma ray background results 
10 | $\mathrm{P}$ a g e

compared to lower energy PIXE, in geological materials in orders of magnitude development in limits of detection $\mathrm{E}=40 \mathrm{MeV}$ (Durocher, et. al., 1998) for high Z elements.

The interpretation of K-X-ray peaks in the spectrum for rare earth elements detected using an intrinsic Ge detector (Chaves, et. al., 2014) considerably easy in comparison to fitting of L-X-rays below $10 \mathrm{keV}$. The systematically calculated the X-ray production cross sections of the REE from 40-70 MeV and will use the results to geo materials like charnockite. The possibility of using off-line counting of delayed rays, following activation of the sample by the high energy protons provides further analytical possibilities. While the use of high energy proton PIXE may dominates the experimental uncertainties of multielement interferences, the expense and limited access to high energy experiments will prevent this becoming wider spread analytical techniques.

So, it might be expected that PIXE with high-energy proton bombardment of charnockite complex geological materials may cause a number of nuclear reactions, with the result that low-energy gamma-rays from those reactions could interfere with the X-ray spectra of the elements of interest. This is to some extent borne out by the experiment who observed peaks in their spectra that they interpreted to be "of nuclear origin." In this case, the projectiles used were protons, and the peaks of nuclear origin were produced when the energy of the protons was raised. However, reported well-resolved $\mathrm{K}$ line spectra for the rare-earth elements (REEs) in several geological materials, showing that interference due to low-energy gamma-rays and from nuclear reactions is not a necessary result of using high-energy protons for excitation.

It has been concluded also that the "gamma-rays Compton scattering within the Ge detection might importantly increase the background for studies run at high energies proton $30 \mathrm{MeV}$ (Ishii, 1995), to the extent that this component of the background might effectively obscure K X-ray peaks. We have shown that this is not the case. From the previous experiments in case of geological materials, we see that the K-X-rays from various elements are clearly resolved with high peak-to-background ratios, and that high levels of bremsstrahlung are not an important problem. These experiments are to be expected, as the ionization cross section for K-shell of REE and high-Z elements reaches a maximum in the proton energy range 30-60 MeV (Hajivaliei, et. al., 2000). Because of the present study in the determination of high $\mathrm{Z}$ elements in charnockite composition, it seemed worthwhile to focus the analytical potential in this area of HE-PIXE.

Therefore, the matrix chanockite analysis by using PIXE with $3 \mathrm{MeV}$ proved good results (Macarthur and Ma, 1991) at media Z elements. Of course interferences are takes place due to matrix charnockite contained wide range of elements. PIXE with $3 \mathrm{MeV}$ failed to detect very low $\mathrm{Z}$ elements due to detector limits and also at high $\mathrm{Z}$ elements due to overlapping of these L-X-rays of high $\mathrm{Z}$ with $\mathrm{K}-\mathrm{X}$ - rays of low and middle $\mathrm{Z}$ elements, detection not is possible. Simultaneously K-X-rays cross sections are heavy at low energy protons, so $3 \mathrm{MeV}$ proton is not sufficient to excite the elements at high $\mathrm{Z}$ elements. HE-PIXE is required for the analysis of high $\mathrm{Z}$ elements present in the charnockite composition with alternation for gamma rays in addition to the high energy K-X-ray detection. 


\section{Conclusions}

The elements in the Precambrian charnokite complex composition $\mathrm{Cl}, \mathrm{K}, \mathrm{Ca}, \mathrm{Ti}, \mathrm{V}, \mathrm{Cr}$, $\mathrm{Mn}, \mathrm{Fe}, \mathrm{Ni}, \mathrm{Cu}, \mathrm{Zn}, \mathrm{Se}, \mathrm{Br}, \mathrm{Rb}, \mathrm{Sr}, \mathrm{Y}, \mathrm{Zr}, \mathrm{Nb}, \mathrm{Mo}, \mathrm{Ru}, \mathrm{Ag}, \mathrm{Pb}$ are measured with errors due to interferences by PIXE spectrum. The elements minor and major elements Li. B, F, Na, Mg, $\mathrm{Al}, \mathrm{Si}, \mathrm{P}, \mathrm{Ba}$ and traces of $\mathrm{Sc}, \mathrm{Ce}, \mathrm{Co}, \mathrm{Sn}, \mathrm{W}, \mathrm{Ge}, \mathrm{Ga}, \mathrm{Au}, \mathrm{Th}, \mathrm{U}$ and REE are not detected due to the experimental factors even though there present in the charnockite composition from previous analytical techniques. Because of characterization of Charnockite mineral the investigation at PIXE which is operation at $3 \mathrm{MeV}$ energy.

From the above discussion, the results of high $\mathrm{Z}$ elements are to be expected, as the cross section for $\mathrm{K}$-shell ionization of medium to high- $Z$ elements reaches a maximum in the proton energy range of $30-50 \mathrm{MeV}$ in case charnockite matrix composition. It has been suggested that the interference of these discrete, gamma-rays with the X-ray spectrum is a serious problem in HE-PIXE work, sufficient to preclude its use as a viable analytical technique.

The systematically measured the $\mathrm{X}$-ray production cross sections of the high $\mathrm{Z}$ and REE from $40-70 \mathrm{MeV}$ and will apply the results to geological samples. The approach is possible to avoid these interferences separation of REE from the matrix or by analysing the K-X-rays instead of the L-X-rays for the REE in a bulk sample. The interpretation of K-X-ray peaks for the REE detection using an intrinsic Ge detector is valuably simple in comparison to $\mathrm{Si}(\mathrm{Li})$ interpretation of L-X-rays below $10 \mathrm{keV}$.

PIXE with $3 \mathrm{MeV}$ failed to detect very low $\mathrm{Z}$ elements due to detector limits and also at high $\mathrm{Z}$ elements and hence overlapping of these L-X-rays of high $\mathrm{Z}$ with $\mathrm{K}-\mathrm{X}$ - rays of low and middle $\mathrm{Z}$ elements, detection not is possible. Simultaneously $\mathrm{K}$-X-rays cross sections are heavy, so $3 \mathrm{MeV}$ proton is not sufficient to excite the elements at high $\mathrm{Z}$ elements. To analyse the charnockite composition completely using PIXE, by using previous literature of charnockite and geological research, most probably HE-PIXE may enable.

\section{Acknowledgment}

I deem it a privilege to express my deep sense of gratitude and heartiest thanks to my research director. I am thankful to Prof A. Durga Prasad Rao, Head of the Department, Department of Nuclear Physics, Andhra University, Visakhapatnam and teaching staff. The deep sense of gratitude and heartiest thank to Prof. Y. Rama Krishna, Head of the Department, Engineering Physics, Andhra University, Visakhapatnam. I thank Dr. D. P. Mahapatro, Director, Institute of Physics, and Bhubaneswar, providing an accelerator facility to carry out the research work and for all amenities provided during our stay at the institute of physics. 
12 I P a g e

\section{References}

[1] Campbell, J L., Willcam, J. (1995) PIXE analysis of Mineralogy and Geochemistry, The Canadian Mineralogist. 33, pp. 93-302.

[2] Chaves, P C., Taborda, A., Deoliveira, D P S., Reis, M A. (2014) Cd-Te detector based PIXE mapping of geological samples. Nuclear Instruments and Methods in Physics Research Section B: Beam Interactions with Materials and Atoms. 318, pp. 37-41.

[3] Christopher, M Heirwesh., John, L Campbell., Gerald, K Czamanske. (2016) Refinement of major, minor element PIXE analysis of rocks and mineral. Nuclear Instruments and Methods in Physics Research Section B: Beam Interactions with Materials and Atoms. 366, pp. 40-50.

[4] Durocher, J J G., Halden, N M., Hawthorne, F C., McKee, J S C. (1988) PIXE and micro PIXE analysis of minerals at $\mathrm{Ep}=40 \mathrm{MeV}$. Nuclear Instruments and Methods in Physics Research Section B: Beam Interactions with Materials and Atoms. 30, pp. 470-473.

[5] Graham, C W., John , C R., John, L C., Zdenek, N., \& William, J T. (2002) Application of PIXE to mineral characterization. Nuclear instruments and methods in physics research B; Beam Interactions with Materials and Atoms. 189, pp. 387-393.

[6] Hajivaliei, M., Puri, Sanjiv., Garg, M L., Mehta, D., Kumar, A., Chamoli, S K., Avasthi, D K., Mandal, A., Nandi, T K., Singh, K P., Singh, Nirmal., Govil, I M. (2000) K and L Xray production cross sections and intensity ratios of rare earth elements for proton impact in the energy range 20-25 MeV. Nuclear Instruments and Methods in Physics Research Section B: Beam Interactions with Materials and Atoms. 160, pp. 203-215

[7] Ishii, K., Yamazaki, H., Matsuyama, S., Galster, W., Satoh, T. and Milos, Budnar. (2005) Contribution of atomic bremsstrahlung in pixe spectra and screening effect in atomic bremsstrahlung. X-Ray Spectrometry, 34(4):363-365.

[8] Javier, M. (1996) Low energy PIXE: advantages, drawbacks, and applications. Nuclear Instruments and Methods in Physics Research B: Beam Interactions with Materials and Atoms. 118, pp. 346-351.

[9] Johansson, S A E, Johansson, T B. (1976) Analytical applications of particle induced Xray emission. Nuclear Instruments and Methods in Physics Research B: Beam Interactions with Materials and Atoms. 137, pp. 473.

[10] Kamineni, D C., Bandari, M., Rao, A T. (1982) Halogen-bearing minerals from Airport Hill, Visakhapatnam, India. American Mineralogist. 67, pp. 1001-1004. 
13 | P a g e

[11] Macarthur, J D., Ma, Xin-Pei. (1991) A review of Particle Induced X-ray Emission in geology. International PIXE. 1, pp. 311-338.

[12] Malmqvist, K G., Bage, H., Carlesson, L E., Kristiansson, K., Malmqvist, L. (1987) New methods for mineral prospecting using PIXE and complementary techniques. Nuclear Instruments and Methods in Physics Research B: Beam Interactions with Materials and Atoms. 22, pp. 386-393.

[13] Maxwell, J A., Teesdale, W J., Campbell, J L. (1995) The Guelph PIXE software package II. Nuclear Instruments and Methods in Physics Research B: Beam Interactions with Materials and Atoms. 95, pp. 407-421.

[14] Murozono, K., Ishii, K.,Yamazaki, H., Matsuyama, S., and Iwasaki, S. (1999) PIXE spectrum analysis taking into account bremsstrahlung spectra. Nuclear Instruments and Methods in Physics Research Section B: Beam Interactions with Materials and Atoms. 150(1), pp.76-82.

[15] Norman, M. Halden., John, L. Campbell., William, J. Teesdale. (1995) PIXE analysis in mineralogy and geochemistry, The Canadian Mineralogist. 33, pp. 293-302.

[16] Rao, K S R., Rao, A T., Sriramadas, A. (1969) Porphyritic plagioclase-hornblendepyroxene granulite from charnockitic rocks of Chipurupalli, Visakhapatnam district, Andhra Pradesh, South India, Mineral Geological Magazine. 37, No. 288.

[17] Rao, A T., and Babu, V R R M. (1978) Allanite in Charnockites rock airport hill near Visakhapatnam, Andhra Pradesh. American Mineralogist. 63, pp. 330-331.

[18] Rao, A T., Rao, J U., and Masaru, Yoshida. (1993) Geochemistry and Tectonic Evolution of the Pyroxene Granulites from Visakhapatnam Area in the Eastern Ghats Granulite Belt, India Journal of Geosciences. 36, pp. 135-150.

[19] Ryan, C G. (2004) Ion beam microanalysis in geoscience research. Nuclear Instruments and Methods in Physics Research Section B: Beam Interactions with Materials and Atoms. 219-220, pp. 534-549

[20] Satyanarayana, A V S., Ravi Kumar, S \& Sharma, S V R A N. (2016) An application of PIXE technique to Proto Crustal Rocks: Geo chemical Evaluation of Granulitic Charnockites of Eastern Ghats, Andhra Pradesh, Journal of Nuclear Physics, Material Sciences, Radiation and Applications, 3(2), pp. 147-155.

[21] Satyanarayana, A V S., and Ravi Kumar, S. (2017) Geochemical analysis of minerals from Charnockite Hill, Visakhapatnam, Andhra Pradesh, India. Indian Journal of Geosciences, Geological Society of India. 71 (2): 435-438.

[22] Satyanarayana, A V S., Jagannadha Rao., M., Chandra Mouli, K., Seetarami reddy, B. (2020) The Performance of PIXE Technique through a Geochemical Analysis of High Grade 
14 | P a g e

Rocks. Journal of Nuclear Physics, Material Sciences, Radiation and Applications, 7(1), 1328.

[23] Satyanarayana, A V S., Jagannadha Rao, M., Sai Satya Mounika, K. (2020) Need of Complementary Analytical Technique at PIXE-Complex Matrix Composition Analysis, International Journal of Scientific Research in Physics and Applied Sciences, 8(3), pp. 36-40.

[24] Satyanarayana, A V S., Jagannadha Rao, M., Chandra Mouli, K., Sai Satya Mounika, K.. (2020) Performance of PIXE Technique at Elemental Analysis of Halogens in Charnockite Matrix, International Journal of Scientific Research in Physics and Applied Sciences, 8(4), pp.1-6.

[25] Sven, A E Johansson and John, L Campbell. (1988) PIXE: A novel technique for elemental analysis, Wiley New York. Vol. 47.

\section{Conflict of Interest; Authors have no conflict of interest}

\section{Code and Data Availability;}

Satyanarayana, A V S., Jagannadharao, M., Chandra Mouli, K., Seetarami Reddy, B. (2020). The Performance of PIXE Technique through a Geochemical Analysis of High Grade Rocks. . Journal of Nuclear Physics, Material Sciences, Radiation and Applications, 7(1), 1328. https://doi.org/10.15415/jnp.2019.71002

Satyanarayana, A V S. Ravi Kumar, S and Sharma, S.V.R.A.N. (2016) An application of PIXE technique to Proto Crustal Rocks: Geo chemical evaluation of Granulitic Charnockites of Eastern Ghats, Andhra Pradesh, India. . Journal of Nuclear Physics, Material Sciences, Radiation and Applications, 3(2), 147-155. https://doi.org/10.15415/jnp.2016.32016

\section{Competing interests;-}

Sir, this is a part of research work at Andhra University, Visakhapatnam, and Andhra Pradesh, India. The topic related to material analysis by using PIXE technique and also the limitations of technique. The limitation arises due to selecting material which is very complex matrix material. Also it gives the idea where the PIXE fails to determine the elements, simultaneously gives the idea of another complementary technique which is used to give the complete analysis of the complex materials.

\section{Authors have no conflict of interest}

\section{Funding;-}

No funding, it is my own research work under the guidance of Prof. M. Jagannadha Rao

\section{Authors' contributions;-}

The first author Dr. A.V.S. Satyanarayana, being a Nuclear Physics graduate he is instrumental in the design of the experiment, sample preparation, selection of appropriate 
15 I P a g e

476 standards for the PIXE analysis, having discussions with the scientists of PIXE facility to 477 come up with standard analytical conditions for the rock with complex matrix to be analyzed 478 that is charnockite and compared with complementary present AAS \& previous others. He 479 contributed all the technical aspects of PIXE analytical work, including physically working 480 with experts at PIXE facility.

The second author Prof. M. Jagannadha Rao is a Geologist having vast knowledge of 482 Eastern Ghats from which the analyzed Rock samples of charnockites are collected. His 483 contribution is selection of standard samples from field keeping in mind the sample location 484 which is very important in understanding its genesis, based on the geochemical data obtained 485 from PIXE. He also suggested suitable international standards which are close to the 486 charnockite. Both the authors together finalized the data, including error calculation, 487 interpretation and formatting the paper.

488 The third author Prof. B. Seetharami Reddy is a Physicist having vast knowledge of 489 Nuclear Techniques especially in PIXE from which the analyzed Rock samples of 490 charnockites are collected. His contribution is selection of standard samples and analysis 491 from field keeping in mind the sample location which is very important in understanding its 492 genesis, based on the geochemical data obtained from PIXE spectrum and experimental 493 factors. He also suggested suitable international standards which are close to the charnockite. 